\title{
PRIMORDIAL À BOA GOVERNANÇA: ACCOUNTABILITY DE PERFORMANCE
}

Poucas ideias são tão primordiais à boa governança quanto o accountability.

Considerando-se que o aspecto central da governança é a definição sobre como o poder é alocado e exercido dentro da sociedade (e o modo particularista desta alocação refere-se precisamente à corrupção), há uma preocupação de caráter republicano em estabelecer controles e fechaduras ao desempenho deste poder político.

Tais constrições incorporam-se ao dever permanente de prestação de contas por parte dos agentes públicos e mandatários, resultante das responsabilidades que decorrem da delegação funcional outorgada pelo contrato social. É o que está exposto na Declaração dos Direitos do Homem e do Cidadão, de 1789, em seu art. 15: a sociedade tem direito de pedir contas a todo agente público pela sua administração.

A concepção do termo accountability segue, desta feita, o predicado fundamental de que os negócios do estado são também negócios do povo. ${ }^{408}$ Assim, àqueles a quem cabe agir em nome da sociedade, recai a obrigação inarredável de expor, minudenciar, apontar e justificar como, o porquê e para aonde estão sendo destinados os recursos coletivos. Veja, se você contrata um corretor ou um advogado para atuar em seu nome, representando interesses que lhe pertencem, é natural que, em virtude da assimetria de informações que existe entre você e o mandatário,

408 "A simples menção do termo república já evoca um universo de conceitos, intimamente relacionados entre si, sugerindo a noção do princípio jurídico que a expressão quer designar. Dentre tais conceitos, o da responsabilidade é essencial (ATALIBA, Geraldo. República e Constituição. 3. ed. São Paulo: Malheiros, 2011, p. 38). 
este tenha que (durante ou após a prestação do serviço) apresentar-lhe os resultados obtidos. A relação política estabelecida entre governantes e governados orienta-se por pressupostos semelhantes. Lógico, adicionada a complexidade resultante da pluralidade em ambos os polos desta relação. São milhões de governados e algumas centenas de governantes, além de aspectos inteiramente novos, como a presença da burocracia governamental, estabelecendo outras relaçôes. ${ }^{409}$

A boa administração exige que os agentes públicos e responsáveis pela condução da política prestem contas pelo que fazem ou não, e pelas decisões que tomam ou deixam de tomar.

Este modelo clássico é chave para nossa compreensão sobre a qualidade da democracia e da governança pública. Em termos gerais, accountability corresponde ao passivo que vem a equilibrar o ativo do poder, pois traduz a ideia de reconhecimento de uma dívida em face dos cidadãos, que é a rendição de contas. ${ }^{410}$ Traduz, em verdade, o que a física denomina de força do retrocesso, a qual leva o poder a voltar periodicamente ao seu ponto de origem, no caso, o povo.

De modo semelhante ao sistema jurídico de pesos e contrapesos, os mecanismos de prestação de contas mitigam os riscos que comporta todo processo de delegação de poder, dentre eles, o de que, ao invés de basear-se em princípios democráticos, o governo representativo seja estruturado por trocas de favores clientelistas, centralizando o poder político e os privilégios auferidos a partir dele.

Por isso é que, nas palavras de Ronald Dworkin, na democracia, aqueles que estão no exercício do poder público não devem ser os únicos juízes de suas próprias decisōes. ${ }^{411}$

Além do mais, a interação entre sociedade e Estado envolve um traço de confiança que suscita obrigaçôes díspares para cada ator. Explico. Enquanto os cidadãos em geral estão acobertados, plenamente, pelo direito fundamental à presunção de sua inocência, as autoridades públicas, precisamente pela natureza pública dos interesses que representam, devem atuar sob constante vigilância, razão pela qual precisam, sem qualquer exigência prévia, apresentar provas de sua inocência e lisura. É o que Madison pretendeu esclarecer, ao salientar, n’O Federalista n. 57,

409 Verifica-se o surgimento de uma nova relação de delegação. Na medida em que surgem problemas complexos referentes às políticas públicas, os agentes políticos (agora no papel de principal) delegam autoridade para uma burocracia extensa, complexa e técnica.

410 BEAUD, Oliver; BLANQUER, Jean-Michel. La responsabilité des gouvernants. Paris: Descartes e Cie., 1999, p. 12.

411 DWORKIN, Ronald. O direito da liberdade: a leitura moral da Constituição Norte Americana. São Paulo: WMF Martins Fontes, 2006. 
que o objetivo de toda a constituição política é tomar precauções as mais efetivas para manter os governantes virtuosos enquanto continuarem a ser fiduciários públicos. Esta característica peculiar diferencia a democracia de outros regimes, ao possibilitar que cidadãos informados escrutinem a conduta governamental, contestando opções políticas e prevenindo o desenvolvimento da concentração de poder em instâncias particulares. ${ }^{412}$

Para que compreendam porque este é o capítulo que encerra o paradigma sobre o governo aberto (bem como este livro): o accountability completa o ciclo de boa governança e controle, iniciado pelo conhecimento do cidadão a respeito das estruturas e processos estatais (a prestação de contas é deficiente quando a sociedade não dispõe de informações completas), sucedido pela inserção desta no espaço de decisão pública, e que continuará girando para assegurar governos mais eficientes e menos corruptos.

Quanto maior a possiblidade de os cidadãos discernirem que a administração está atuando em benefício dos interesses públicos e conseguirem impor restrições para que ela não fuja deste escopo em prol de interesses particulares, mais "accountable" é o governo.

A ênfase nas formas de accountability governamental, segundo Daniel Kaufman, retrata a crescente preocupação em combater a corrupção e promover integridade no setor público. ${ }^{413}$ É também um modo de afiançarmos que as instituições não estão sendo objeto de captura por grupos seculares adaptados a incrementar sua própria riqueza à custa do tesouro público.

Afinal de contas, o que é accountability?

A complexidade que envolve esta questão não permite que respondamos de forma satisfatória em poucas linhas. Tentativas de obter uma definição objetiva e cujos critérios fossem minimamente críveis do ponto de vista teórico foram objeto de centenas de livros, artigos, compêndios e palestras.

No Brasil, Anna Maria Campos, em artigo publicado no início da década de 1990, procurou jogar alguma luz sobre o assunto, ao problematizar se o termo poderia encontrar tradução na língua portuguesa. ${ }^{414} \mathrm{O}$ desafio seria relançado 20

412 O hábito de questionar constantemente as autoridades garante maior liberdade do que qualquer outro sistema social baseado na representação (BRIN, David. The transparent society. MA: Addison-Wesley Longman, Inc., 1998).

413 KAUFMAN, Daniel. Myths and realities of governance and corruption. World Bank Governance Program, Washington, DC, 2005.

${ }^{414}$ CAMPOS, Anna Maria. Accountability: quando poderemos traduzi-la para o português? Revista de Administração Pública, n. 24, p. 30-50, fev./abr. 1990. 
anos mais tarde, no trabalho de José Antônio Gomes de Pinho e Ana Rita Silva Sacramento, questionando se já seria possível a tradução da palavra accountability para o português, revelando a dificuldade teórica que circunda este tema. ${ }^{415} \mathrm{Em}$ ambos, concluiu-se que a abrangência semântica e as múltiplas ramificações teóricas da expressão de origem inglesa impedem a correspondência adequada para uma única palavra do dicionário português.

Assim, o significado permanece aberto, sem estruturas completamente definidas. Com efeito, os elementos que compõem a conceptualização, tais como agente, objeto, limites e mecanismos, variam conforme o autor, gerando uma confusão conceitual. O objetivo neste capítulo, contudo, não é aprofundar nos ramos da ciência política que estudam o accountability, tampouco relançar a pergunta sobre sua tradução, senão apenas explorar suas implicações e efeitos na transição à boa governança. Uma análise superficial das abordagens, contudo, não deixa de ser necessária.

Accountability costuma ser definido, primariamente, como um modo de identificar malversações públicas e punir os indivíduos ou organizaçōes que não agiram conforme a lei, especialmente se os comportamentos envolverem corrupção. ${ }^{416}$ Desta forma, o instituto sempre esteve associado à ideia de responsabilização frente a alguma determinação legal (liability), pois, aquele que falha no cumprimento de diretrizes normativas é considerado irresponsável, sujeitando-se às penalidades.

Tal perspectiva sancionatória encontra sustentação numa ideia de liberalismo do medo ${ }^{417}$ ou naquilo que Rosanvallón chama de desconfiança liberal, ${ }^{418}$ fundada no receio de que as autoridades públicas estão invariavelmente inclinadas a abusar dos poderes, ou se valerem deles para obter benefícios privados, de modo que o accountability constituiria uma limitação às intempéries da discricionariedade política.

Esta abordagem encontra correspondência, também, na classificação de Guillermo O'Donnell, como um accountability de natureza vertical, referente ao procedimento eleitoral. Isto é, são os cidadãos-eleitores que manifestam a habilidade de

415 PINHO, José Antônio Gomes de; SACRAMENTO, Ana Rita Silva. Accountability: já podemos traduzi-la para o português? Revista de Administração Pública [online]. v. 43, n.6, p. 13431368, 2009.

416 PETERS, Guy B. Performance-based accountability. In: SHAH, Anwar (Ed.). Performance Accountability and Combating Corruption. Washington D.C.: The World Bank, 2007.

417 SHKLAR, Judith. The liberalism of fear. In: HOFFMAN, Stanley (Ed.). Political thought and political thinkers. University of Chicago Press, 1998.

418 ROSANVALLÓN, Pierre. La contrademocracía: la política em la era de la desconfianza. Buenos Aires: Manantial, 2015. 
punir os agentes políticos, ao utilizarem as urnas para reelegê-los ou não. Ou melhor, os governos são accountable na medida em que cidadãos-eleitores puderem discernir se os governantes estão atuando a serviço do interesse da coletividade, de tal forma que aqueles representantes que agirem em benefício deste interesse vencerão a reeleição e aqueles que não o fizerem, perderão. ${ }^{419}$

Ocorre que os governos tomam centenas de decisões, cotidianamente, que afetam a vida das pessoas e, nessa medida, a manutenção do instrumento eleitoral como modelo exclusivo de vigilância é insuficiente para controlar milhares de metas governamentais.

A arritmia inerente às eleições permite apenas que os cidadãos homologuem ou não, em intervalos prefixados de tempo, os programas e ações tomadas pelos governantes, analisando de forma retrospectiva informações sobre o desempenho passado. Tal teoria retrospectiva do accountability, embora necessária, é incompleta, vez que a avaliação eleitoral não é tão racional e eficiente quanto parece $a$ priori, pois a conduta dos eleitores é comprovadamente suscetível a influências aleatórias e dissociadas da performance dos governos, criando incentivos para que representantes elaborem políticas que favoreçam a reeleição, em detrimento de programas íntegros que impactem o bem-estar dos cidadãos de forma duradoura. Neste quadrante, os agentes políticos estão continuamente sob o dilema de obter cada vez mais recursos para sustentar-se no poder, bem como promover projetos direcionados aos grupos que o apoiaram. Bem assim, as eleiçôes acabam não forçando os candidatos eleitos a refletir preferências políticas dos eleitores, ou seja, não geram controle popular sobre as políticas implementadas. Em síntese: não produz accountability eficiente. ${ }^{420}$

Além do mais, concentrar os mecanismos de accountability nas eleições acarreta, também, dificuldades em vislumbrar como os governantes seriam responsivos às minorias e grupos marginalizados, promovendo igualdade na alocação dos recursos públicos. Em virtude desta circunstância é que Jeremy Waldron, ex-ministro da Suprema Corte norte-americana, assevera que a visão limitada do instituto subdimensiona a exata contribuição para o nosso entendimento sobre democracia. ${ }^{421}$

419 PRZEWORSKI, Adam; MANIN, Bernard; STOKES, Susan C. Eleição e representação. Lua Nova, São Paulo, n. 67, p. 105-138, 2006.

${ }^{420}$ ACHEN, Christopher H.; BARTELS, Larry M. Democracy for realists: why elections do not produce responsive government. United Kingdom: Princeton University Press, 2016.

421 WALDRON, Jeremy. Accountability: fundamental to democracy. NYU School of Law, Public Law Research Paper n. 14-13, 2014. 
A incapacidade do modelo baseado, exclusivamente, nos ritos eleitorais de produzir governos responsivos foi notada pela ciência política, dando azo à elaboração de formas de accountability não eleitoral que superassem a intermitência das urnas, proporcionando meios de controle formal e informal no curso do mandato. ${ }^{422}$ Desta feita, aparecem outras denominações e sentidos à palavra, tais como o accountability horizontal, complementar à dimensão vertical, segundo O’Donnell, referente às instituições (ombudsman, auditoria, controladoria etc.) que compõem um sistema interestatal de controle das açôes por parte dos órgãos estatais; ${ }^{423}$ ou a dimensão social, cuja concretização se dá mediante a atividade dos cidadãos comuns, associações civis, veículos de comunicação, e organizações sociais, que se articulam para supervisionar e pressionar o comportamento dos agentes públicos; ${ }^{424}$ ou, ainda, às formas de accountability diagonal e externo, suscitadas por Ricardo Pelizzo e Frederick Stapenhurst. ${ }^{425}$

Inobstante os inúmeros modelos e variações, quero apresentar uma compreensão particular sobre accountability, fruto da experiência que acumulei em duas décadas no exercício do controle externo, e que servirá de base ao argumento que pretendo expor. Concebo o accountability em duas proporções distintas: uma direcionada ao passado, referente à responsabilidade, que reflete a obrigação governamental de explicar seus próprios atos e, eventualmente, responder por eles, sofrendo as consequências legais da desídia ou da desonestidade. A outra direcionada ao futuro, relativa à responsividade, que diz respeito à conversão de preferências em políticas íntegras, eficientes e inclusivas, materializando a legitimidade política que ressoa não apenas das urnas, mas das necessidades cotidianas do povo. ${ }^{426}$

422 Accountability fora da urna, na expressão de Susan Rose-Ackerman. (ROSE-ACKERMAN, Susan. Trust, honesty, and corruption: reflection on the state-building process. Yale Law School, Research Pape n. 255, 2001).

${ }^{423}$ O'DONNELL, Guillermo. Accountability horizontal e novas poliarquias. Lua Nova [online], n. 44, p. 27-54, 1998.

424 "Essa nova forma de política que surge no espaço da sociedade civil engloba uma variedade de formas de ação coletiva que compartilham uma comum preocupação em melhorar o funcionamento das instituições representativas através do fortalecimento dos mecanismos de controle da legalidade dos funcionários públicos”. PERUZZOTTI, Enrique. La política de accountability social em América Latina. 2010. Disponível em: <http://www.lasociedadcivil.org/ wp-content/uploads/2014/11/accountability_social1.pdf>. Acesso em: 16 mar. 2018.

425 PELIZZO, Ricardo; STAPENHURST, Frederick. Legislative oversight tools. Oxford: Routledge, 2011.

426 Trato da noção de legitimidade corrente, abordada pelo STF na ADI n. 5874 MC/DF 2018, cuja prospecção ultrapassa a legitimidade pela investidura (eleição), dizendo respeito à correspondência entre os atos praticados pelo representante e a vontade manifestada pelos representados. 
Não ignoro a importância da responsabilidade (como já ressaltei, que a abordagem sancionatória não deve ceder completamente à política preventiva), assegurando que os agentes estatais respondam pelas condutas que destoem das leis, embora entenda que a responsabilidade aqui encerra outros aspectos, tal como o comprometimento permanente com a integridade.

$\mathrm{O}$ enfoque, também, deve estar voltado àquilo que o Estado produz aos seus cidadãos, mensurando a distância entre intenções e realizações, entre palavras e fatos. Os programas adotados pelo governo estão de fato entregando serviços de qualidade, ou as falhas mais graves estão nos resultados? As políticas conseguem promover igualdade na distribuição de recursos ou aprofundam o sistema clientelista dos caçadores-de-renda? Se existem falhas, quais são as suas causas e como corrigi-las? É crucial compreender estes tipos de falhas ou produção de efeitos perversos que decorrem das políticas, viabilizando a correção de rumos.

Trata-se da espécie de reforma na atitude política a que se refere Susan Rose Ackerman, substituindo as relações corruptas personalizadas pela visão de que o estado tem o dever para com a sociedade de prover serviços públicos justos (que não perpetuem privilégios) e eficientes (que apresentem benefícios sólidos ao bem-estar social). Para facilitar essas atividades, ela afirma, "o poder público provê informações sobre suas ações, e indivíduos e organizações sociais pressionam por accountability. O propósito é aumentar a abertura do governo, deixando-o mais vulnerável à vontade popular". 427

A perspectiva desta dimensão responsiva é futura porque foca no aprimoramento do desempenho ao invés da punição retrospectiva, sendo um meio de institucionalizar uma abordagem de aprendizagem e de direção da governança. ${ }^{428}$ Dentro deste contexto, o bom agente político é aquele que está disposto a direcionar sua atuação às exigências de integridade e interesse público.

Boa síntese do que afirmo foi formulada por Ana Naveira, na Revista de Controle Externo Espanhol, segundo a qual o conceito de accountability há transmutado a uma noção mais ligada à ideia de compromisso com a obtenção de resultados e objetivos programados para as organizaçôes públicas, em complementação à ideia clássica de responsabilidade, associada à percepção de que os funcionários da admi-

427 ROSE-ACKERMAN, Susan. Trust, honesty, and corruption: reflection on the state-building process. Yale Law School, Research Pape n. 255, 2001

${ }^{428}$ PETERS, Guy B. Performance-based accountability. In: SHAH, Anwar (Ed.). Performance Accountability and Combating Corruption. Washington D.C.: The World Bank, 2007. 
nistração deviam responder pelas suas decisões e atos frente à sociedade, através de uma série de regras legalmente preestabelecidas. ${ }^{429}$

\section{Fala-se, então, do accountability de performance.}

$\mathrm{Na}$ verdade, tal abordagem do controle acompanha a evolução da própria maneira de reger os negócios públicos. Influenciado pelas reformas administrativas ocorridas na Inglaterra e Estados Unidos, na década de 1970-1980, o Brasil buscou adotar o paradigma da administração gerencial (New Public Managment) em substituição ao modelo usual burocrático de Weber, com vistas a tornar a administração pública mais eficiente. Assim, sobretudo a parte do Plano Diretor de Reforma do Aparelho do Estado, de 1995, diversas técnicas foram importadas do setor privado com o fim de aprimorar os serviços públicos, de modo que esta nova gestão pública fosse orientada pelos resultados proporcionados e como eles impactam a vida e o bem-estar dos stakeholders, neste caso, os cidadãos. Neste paradigma de reformulação da agenda de Estado, o controle (accountability) também foi objeto de transformação, na medida em que deslocou o foco de avaliação da legalidade estrita puramente destinada à sanção, isto é, da mera checagem de atendimento da conduta dos agentes a regras e protocolos, para a centralização do desempenho da administração, a partir das lentes da eficiência, moralidade e vedação ao desperdício.

A noção de boa administração pública, portanto, fornece referência à evolução do accountability, que adota a legalidade como ponto de partida, mas não termo de chegada, sobrelevando a produção de resultados positivos e com efeitos positivos sobre a coletividade. Presta-se contas pelas açôes que se executa, mas também pelas expectativas que se cria.

O núcleo duro deste accountability de performance é que ele não enfatiza eventos excepcionais negativos (falhas puníveis), mas o desempenho positivo das organizaçōes. Não obstante a imposição de controles com vistas à sanção torne a corrupção mais difícil, elas certamente não tornam mais fácil agir de forma íntegra e eficiente. É preciso pensar um sistema que apoie a escolha certa, ao invés de apenas rechaçar as escolhas erradas. Que torne fácil, pois, o caminho à boa governança.

Sistemas que utilizam a performance como critério para exercício da fiscalização exigem que ao invés de pensar sobre as consequências e imputações de culpabilidade aos agentes irresponsáveis, realce a utilização de indicadores que demonstrem o sucesso ou fracasso das políticas públicas, fornecendo soluçōes eficazes no último caso. Procura-se assegurar que valores públicos são gerados a partir do

429 NAVEIRA, Ana M. El funcionamiento de la administración bajo um sistema de dirección por objetivos: una necesidad y un nuevo enfoque para los órganos de control. Revista Española de Control Externo, v. XVII, n. 49, p. 39-63, Enero 2015. 
dinheiro gasto pelo governo, e que os recursos não são alocados particularmente. Não por acaso essa abordagem sobre performance é designada pela OCDE como value for money. ${ }^{430}$

No entanto, a realização desta matriz do accountability depende do preenchimento de duas condições essenciais. A primeira delas é a capacidade dos cidadãos de influir na definição das metas coletivas da sociedade, habilidade à qual Robert Dahl se refere como definição da agenda política pelos cidadãos. ${ }^{431} \mathrm{~A}$ segunda diz respeito ao desenvolvimento de mecanismos que garantam o controle das ações dos governos em termos de produção de resultados, possibilitando uma confrontação direta entre as contas rendidas pelos agentes sobre aquilo que foi feito e os critérios de avaliação do desempenho, de maneira que os aprendizados adquiridos permitam criar padrões sólidos de boa governança.

O desafio central quando falamos em políticas governamentais e seu controle é saber o que funciona e porque funciona, para que surjam oportunidades de melhoramento progressivo e constante. Importa saber, portanto, como desenvolver este sistema que utiliza o desempenho como instrumento de accountability. Vamos por partes. ${ }^{432}$

De início, presumindo que estaria preenchido o pressuposto que mencionei acima no tocante à definição da agenda política de metas pelo povo, o governo precisa ter uma visão clara do sucesso ou fracasso dos programas que pretende implementar, ou seja, deve determinar quais resultados espera alcançar com as políticas públicas a serem implementadas (outcomes).

Ademais, é igualmente salutar determinar os passos intermediários no processo. Por exemplo, avaliar o desempenho das políticas de educação pública exige que examinemos o nível de financiamento, o dispêndio por aluno, entre outros aspectos que influenciam no resultado (outputs). No Brasil, em 2014, o gasto com educação, em porcentagem do orçamento, superou o de países como Suíça e Dinamarca, embora a média das notas no PISA e a qualidade dos serviços sejam profundamente inferiores. ${ }^{433}$

430 OECD (2010). Value for money in government: public administration after "new public management" 2010.

431 DAHL, Robert A. A democracia e seus críticos. Tradução de Patrícia de Freitas Ribeiro. São Paulo: WMF Martins Fontes, 2012.

432 Aqui, utilizo como referência as etapas de accountability de performance apresentadas por Guy Peters: PETERS, Guy B. Performance-based accountability. In: SHAH, Anwar (Ed.). Performance accountability and combating corruption. Washington D.C.: The World Bank, 2007.

433 Em porcentagem do PIB, o Brasil (4,9\% do PIB) está próximo da média dos países da OCDE, que é de 5,2\% do PIB. A despeito disso, o Brasil continua ocupando as últimas posições do ranking dos testes de avaliação do PISA. OCDE. Education at a Glance 2017: OECD Indicators, 2017. 
Em terceiro, e como consectário da definição dos produtos almejados, deve-se fixar os padrões adequados de desempenho (metas), ou seja, se o propósito é obter bons resultados, o quanto bom é bom o suficiente? Quanto de desenvolvimento é adequado para indicar que o programa e a sua gestão estão funcionando satisfatoriamente? A que altura posicionará o sarrafo?

Finalmente, insisto, muito embora a ênfase do controle tenha se deslocado do caráter sancionatório, para o exame da performance e aprimoramento da governança, é importante esclarecer que a ineficiência geralmente anda ladeada pela corrupção, razão pela qual não se deve negligenciar o delineamento de responsabilidades. Tal aspecto assume contornos ainda mais relevantes, diante da complexidade dos sistemas administrativos modernos, cujos centros de decisão encontram-se cada vez mais descentralizados.

Enfim, apoiar-se em metas e indicadores na formulação e avaliação de ações no setor público não representa bem uma novidade, mas as potenciais vantagens deste modelo são ainda subvalorizadas.

Na Espanha, a Ley n. 19/2013 acrescentou o art. $6^{\circ}$ à lei de acesso à informação espanhola, prevendo que: as administraçóes públicas publicarão os planos e programas nos quais se fixem objetivos concretos, assim como as atividades, meios e tempo previsto para a consecução. Seu grau de comprometimento e resultados deverá ser objeto de avaliação e publicação periódica junto com os indicadores de medida e valoração, de forma que se determine cada administração competente. Disposição semelhante consta, desde 2001, na Lei Orgânica das Finanças, que nos arts. 48 e 51 indicam que o governo deve informar missões, programas e indicadores de rendimento. Nos Estados Unidos, o Government Performance and Results Act vigora desde 1993.

Para nós, acredito, há um longo caminho a ser percorrido.

Isso porque nossas políticas, sobretudo em nível local, são predominantemente calcadas em ideologismos ou marketing baratos, que não raras vezes servem apenas como pretextos para o direcionamento velado de recursos públicos ou oportunidades para o rent-seeking predatório. Boa parte dos programas implementados no país não são avaliados, e mesmo quando são objetos de alguma análise técnica, seus resultados são ignorados. Assim, evidências que dariam suporte prático à eficiência e continuidade de boas políticas são sobrepostas pela manutenção de políticas más e criadoras de privilégios, além de aumentar os custos de transação que fomentam a corrupção.

Perde o cidadão, que vê a eficácia dos serviços públicos ser suplantada pela falta de planejamento e gestão racional, ao passo que cai o que costumo chamar de 
delivery institucional, referente à capacidade das instituições públicas de acessar a qualidade dos bens e serviços que estão sendo produzidos e providos por intermédio de suas ações.

A abordagem do delivery organizacional ganhou notoriedade no começo dos anos 2000, no Reino Unido, a partir de um neologismo convertido posteriormente em ciência administrativa: a deliverologia (deliverology), materializada na criação de uma unidade especial junto ao gabinete do Primeiro Ministro britânico (Prime Ministerial Delivery Unit) com o escopo de fornecer avaliaçôes e criar rotinas técnicas de resolução de problemas que ajudariam a administração pública a cumprir as promessas políticas e aumentar a eficiência dos serviços.

A deliverologia baseia-se na identificação clara de prioridades, na definição de metas, na coleção de dados relacionados a tais objetivos e no exercício de vigilância por intermédio de uma unidade especializada (delivery unit), que se reporta sobre as avaliações, direta e regularmente, aos agentes políticos responsáveis. No caso britânico, em quatro anos, a entidade ajudou o governo de Tony Blair a alcançar $80 \%$ das metas estipuladas ao início do mandato. ${ }^{434}$

Segundo Michael Barber, independentemente de preferências ideológicas, por Estados minimalistas ou pela prevalência de mercados autônomos, todos têm interesse em governos que sejam eficazes naquilo - pouco ou muito - que fazem. $\mathrm{O}$ desafio atual das sociedades consiste, pois, em transformar administrações que funcionam à base de espasmos, cujo foco é gerenciar crises e apagar incêndios, em administrações que atuem por padrōes de governança, desenvolvidos por intermédio de processos cíclicos de aprendizagem e avaliação do desempenho em tempo real. ${ }^{435}$

Apesar de recente, a repercussão positiva das unidades de entrega incentivou a adoção, por outros países, de métodos semelhantes em suas administrações. Em 2010, o governo norte-americano criou a instituição de entrega na área da educação (Education Delivery Institute), com o propósito de auxiliar líderes educacionais a implementar estratégias, prioridades e indicadores para aprimorar o ensino público. Mais recentemente, em 2016, o Canadá importou o modelo, ao criar uma Unidade de Entrega junto ao Privy Council Office, órgão de aconselhamento do governo federal. ${ }^{436}$

${ }^{434}$ CENTRE FOR PUBLIC IMPACT. The science of delivering results: past, present and future.

435 BARBER, Michael. How to run a government: so that citizens benefit and taxpayers don't go crazy. United Kingdom: Penguin, 2015, p. 23.

436 CURRAN, Rachel. Will “deliverology” work for the federal government? Policy Options Politiques, 2016. Disponível em: <http://policyoptions.irpp.org/magazines/april-2016/is-deliverology-right-for-canada/>. Acesso em: 12 mar. 2018. 
Não obstante a adoção de formatos semelhantes, a partir da criação de unidades separadas do comando operacional da administração, é possível cogitar tipos diferentes de institucionalização da deliverologia.

Poder-se-ia, por exemplo, vincular a delivery-unit a agências governamentais preestabelecidas, tal como o Ministério do Planejamento, Orçamento e Gestão (MPOG) ou o Ministério da Transparência e Controladoria-Geral da União (CGU), no caso brasileiro, embora acredite que seja preferível destinar esta função a organismos com certo grau de autonomia.

Nos Estados Unidos, tal função foi inserida nas atribuições fiscalizatórias do parlamento, através do Government Performance and Results Act, de 1993. Conforme esta norma, cabe ao Conselho de Desenvolvimento de Performance, a análise trimestral dos dados sobre desempenho dos objetivos prioritários do Governo Federal, reportando-se ao Diretor do Departamento de Gestão e Orçamento. Dentro da análise, o Conselho avalia os processos alcançados durante o trimestre mais recente, bem como a tendência e probabilidade de cumprir o nível de desempenho previsto, categorizando os objetivos prioritários pelo risco de não alcance do nível planejado de performance. Quanto a estes últimos, o Conselho deve identificar prospecçôes e estratégias para o aprimoramento da performance. Além disso, os objetivos prioritários devem ser consolidados em descrições simples no website do governo (31 U.S. Code $\$ 1121$ ).

Outra possibilidade seria promover uma desconcentração, criando unidades de entrega específicas nos órgãos públicos, de modo que cada uma delas desenvolva trabalhos especializados sobre a entidade à qual estão vinculadas. Estas são conjunturas críveis. Porém, entendo que são desnecessárias. Em nosso arranjo institucional, já possuímos uma entidade com expertise e estrutura para exercer o papel das unidades de entrega: os tribunais de contas. Primeiro, porque gozam de autonomia em relação aos poderes constituídos, porquanto encontram-se desvinculados, funcional e estruturalmente, da esfera política, notadamente, do Poder Legislativo. São plenamente capazes de fornecer avaliações isentas e técnicas. Segundo, porque as cortes de contas receberam diretamente da Constituição Federal, a competência para exercer o controle financeiro, contábil, orçamentário, operacional e patrimonial da administração direta e indireta dos poderes da União, dos Estados, Distrito Federal e Municípios (art. 71, da CRFB/88), utilizando como critérios, além da legalidade, a legitimidade, eficácia, efetividade e economicidade. Isto é, foram designadas pelo constituinte para exercer uma espécie de vigilância pública que ultrapassa o exame de conformidade, apontando para novos padróes de supervisão, orientados pela lógica dos resultados e da vedação ao desperdício. 
Alinhando-se à posição acima exposta, a Organização Internacional de Entidades Fiscalizadoras Superiores (INTOSAI), em conferência realizada no Uruguai, em 1998, consignou que as Instituiçōes Superiores de Auditorias (entre elas, os tribunais de contas), deveriam somar aos esforços anticorrupção, o uso de indicadores e informações que apontem riscos de fraude. ${ }^{437}$

Quero dizer, o Brasil, em tese e ao menos desde 1988, dispõe de uma entidade cujas competências inclui a análise sistemática de resultados da administração pública, a fim de incrementar a eficiência e promover accountability de performance. Resta, no entanto, uma mudança de paradigma e percepção das cortes sobre o que consiste uma fiscalização efetiva. Os órgãos de contas poderiam, com o aparato técnico e os dados de que dispõem atualmente, exercer um papel colaborativo importante na criação de metas, implementação de sistemas de monitoramento e avaliação institucional, identificação de contradições que comprometam a boa gestão dos recursos públicos e no apoio técnico aos gestores. Assim, usufruem de um ferramental valiosíssimo, conquanto subutilizado, para disseminar o impacto dos programas estatais, por meio de indicadores, tanto aos gestores, como subsídio ao aperfeiçoamento, quanto aos cidadãos, lhes vocacionando ao exercício do controle social. Tudo isso ajuda a conformar um sistema de integridade e apreço pela eficiência e equanimidade da ação pública, inibindo a capacidade de certos autores em capturar o destino dos recursos coletivos.

Dada a dificuldade em detectar a corrupção apenas por intermédio de auditorias ou procedimentos formalísticos de controle, tendo em vista o contexto opaco no qual ela ocorre, desvendá-la seria certamente mais fácil caso fosse associada a indicadores que revelem más performances. Reitero: tais circunstâncias (ineficiência e corrupção) estão geralmente conectadas. Onde há uma, provavelmente existirá a outra.

São precisamente os indicadores os responsáveis por traduzir o quanto a política em questão foi eficiente (relação custo-benefício), eficaz (sob a expectativa do gestor) e efetiva (sob a expectativa social). Contudo, para que tais indicadores se convertam em instrumentos úteis à sociedade, devem ser, primeiro, claros, de modo que não remanesça dúvida sobre o seu atingimento, segundo, mensuráveis, possibilitando sua identificação através de uma escala de valores (unidades físicas, monetárias, temporais), sem recorrer a itens genéricos e abstratos, terceiro, compreensíveis, de maneira que permita ao povo identificar o sucesso ou o fracasso de

437 DYE, Kenneth M. Corruption and fraud detection by supreme audit institutions. In: SHAH, Anawar (Org.). Performance accountability and combating corruption. Washington D.C.: The World Bank, 2007, p. 309-310. 
- Finanças públicas: travessia entre o passado e o futuro

políticos por indicadores inteligíveis ${ }^{438}$ e, finalmente, comparáveis, assegurando a viabilidade de comparação da performance histórica de uma mesma organização. ${ }^{439}$

O propósito, afinal, é garantir que a sociedade acompanhe de forma permanente o desempenho das organizações, superando a noção anacrônica de accountability formal monofásico, e fornecendo, a partir do controle social consciente, engajado e munido de informações precisas, bases fortes para a extirpação do particularismo, da corrupção, da ineficiência e da imoralidade na administração pública. É preciso coragem para fazer a transição, mas não podemos esquivar-nos dela. Nas palavras de Fernando Pessoa (e não haveria melhor forma de encerrar, pois as ideias e os estudos hão de continuar):

É tempo de travessia

E se não ousarmos fazê-la

Teremos ficado para sempre à margem de nós mesmos.

438 A título de exemplo, o Canadá possui um portal eletrônico que apresenta os indicadores de políticas públicas federais de modo claro e compreensível, no sítio disponível em: <https:// www.canada.ca/en/privy-council/campaigns/mandate-tracker-results-canadians.html?utm_ campaign=not-applicable\&utm_medium =vanity-url\&utm_source=canada-ca_results $>$.

439 BLIACHERIENE, Ana Carla. Controle da eficiência do gasto orçamentário. Belo Horizonte: Fórum, 2016. 